\title{
OBSTACULOS QUE IMPIDEN EL ACERCAMIENTO ENTRE LOS ESTADOS UNIDOS Y CUBA
}

\author{
Edward González
}

Prácticamente, desde el momento en que Fidel Castro asumió el poder en 1959, las relaciones entre los Estados Unidos y Cuba se tornaron tensas. A comienzos de 1960, las dos naciones se trenzaron en un conflicto que se mantendría durante las tres décadas siguientes. A pesar de que el conflicto tuvo altibajos, a veces se atenuó y con frecuencia se reanudó con inusitada intensidad.

En la actualidad, la caída del comunismo, la desaparición de la Unión Soviética y la consiguiente crisis registrada en Cuba, aparentemente podrían dar paso a un posible acercamiento entre Washington y $\mathrm{La} \mathrm{Habana}$. Abandonada en el mundo postcomunista, Cuba ya no está apuntalada por la Unión Soviética, ya no es la cabeza de playa soviética del hemisferio, ni tampoco promueve la revolución en los países vecinos o envía tropas de combate al extranjero para luchar en tierras distantes. La Cuba de 1993 es diferente, ya que abre su economía y mejora sus relaciones con América Latina, Canadá, Europa y otros países.

Estados Unidos también ha cambiado. Ya no le preocupa la Guerra Fría ni está regido por gobiernos movidos por ideologías instintivamente hostiles al régimen de Castro. Bajo el gobierno de Clinton, la Casa Blanca no tiene ningún compromiso con la comunidad cubana exiliada en Florida, puesto que la mayoría de los cubanoestadounidenses de ese estado no votaron por los demócratas.

De este modo, pese a que el Presidente firmó un Decreto Ley para la aplicación de la Cuban Democracy $A c t$, su gobierno no ha tomado ninguna medida para derrocar al régimen de Castro mediante la intensificación de la crisis económica en ese país. En realidad, parece estar menos preocupado del asunto cubano o al menos más flexible al respecto. Por ejemplo, si bien solicitó 28 millones de dólares como financiamiento para Radio y TV Martí, no ejerció gran presión en los tribunales para impedir que el House Appropiations Subcommittee on Commerce, Justice, State and the Judiciary suprimiera, en el pasado mes de junio, el fondo solicitado. El Departamen- 
to de Estado ha advertido a los exiliados instalados en Miami que no deben llevar a cabo ataques a la Isla. Tampoco ha bloqueado el envío de cierto tipo de asistencia humanitaria a Cuba.

No obstante, la solución del conflicto entre Washingten y La Habana no parece inminente. El principal foco de interés del gobierno de Clinton es nacional, mientras que Cuba actualmente no constituye una prioridad de política exterior apremiante ni un asunto favorable internamente. En Cuba, por otra parte, el gobierno de Castro debe considerar la normalización de las relaciones con los Estados Unidos como el medio principal para aliviar la crisis de la Isla. Sin embargo, no da ninguna señal de estar preparado para comprometerse en el tipo de cambio de sistema que podría inducir a la Casa Blanca a iniciar negociaciones.

¿Qué explica esta parálisis de ambas partes cuando el mundo, Cuba y los Estados Unidos han cambiado? Personalmente, sostengo que tanto los nuevos como los viejos intereses "contradictorios" continúan separando fundamentalmente a ambos gobiernos, lo que presenta mayores obstáculos para la normalización. En este sentido, y paradójicamente, también considero que la crisis cubana, que es cada vez mayor, constituye otro impedimento para la solución del conflicto en ambos lados del Estrecho de la Florida. Concluiré con algunas observaciones con respecto a las opciones estadounidenses en materia de política.

\section{La persistencia de intereses contradictorios.}

Hace más de diez años, distinguí tres tipos de intereses en la relación entre los Estados Unidos y Cuba. ${ }^{1}$ Había intereses "congruentes", en que ambos países obtenían ventajas mutuas mediante la cooperación conjunta en campos como los pronósticos del tiempo atmosférico y los huracanes, la demarcación de derechos de pesca y el establecimiento de "secciones de intereses" destinadas a facilitar la comunicación diplomática. Había intereses "conflictivos", que se derivaban del comportamiento y actitudes de las partes en oposición, pero que eran potencialmente negociables y, por lo tanto, solucionables dentro de un arreglo político más amplio. Así, el asunto de la indemnización

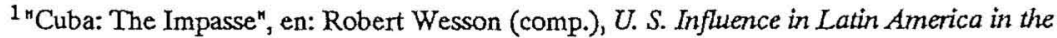
1980s, (Nueva York: Praeger Publishers/Hoover Institution Press, 1982), pp. 198-216.
} 
por los casi 1.800 millones de dólarés en demandas estadounidenses por propiedad nacionalizada - que, en la actualidad puede ser cercana a los 6.000 millones de dólares o más- o el asunto de la dev̈olución de la Bahía de Guantánamo a Cuba, constituyén ejémplos de intereses conflictivos que pueden negociarse y resolverse, siempre que ambas partes estén preparadas para llegar a un arreglo político.

Los Estados Unidos y Cuba no pudieron expandir sus intereses congruentes ni llegar a un acuerdo con respecto a sus intereses conflictivos, ya que sus antagonismos mutuos eran causados intereses "contradictorios" muy arraigados. Estos provenían de un firme apego a principios, formas de comportamiento e intereses u objetivos nacionales específicos que cada nación consideraba esenciales para definir su identidad nacional y su papel a nivel internacional. No podían ser abandonados ni sacrificados por ninguno sin destruir su respectivo poder, condición y autoimagen, tanto en el propio país como en el extranjero.

\section{El internacionalismo cubano y la reacción de los Estados Unidos.}

Durante la década de los setenta, se observó un claro ejemplo de los intereses contradictorios con motivo de la intensa actividad cubana en el campo del "internacionalismo" en nombre de dos de sus aliados en Africa -el MPLA que luchaba por el control de Angola, luego del retiro del mando portugués, y el régimen de Mengistu en Etiopía que era atacado por Somalia-y a propósito de las respuestas estadounidenses a las dos incursiones militares cubanas en la región. Ambos acontecimientos sucedieron en un momento en que las relaciones entre los Estados Unidos y Cuba pasaban por un período de menor tensión, ocasionando nuevas tensiones de tirantez.

En rápida sucesión entre 1975 y 1978, las victorias militares de las Fuerzas Armadas Revolucionarias en Angola y Etiopía lanzaron a Cuba al escenario internacional como actor de rango mundial, aumentaron su prestigio en Africa y en el Movimiento de Países No Alineados, y elevaron la posición de Castro en el Tercer Mundo. Dado que sus triunfos militares y políticos intensificaron el interés soviético en el continentê, Cuba también ganó materialmente al obtener niveles más altos de asistencia militar y económica de la 
Unión Soviética que el recibido en el período anterior a 1976. En efecto, Cuba asumió una relación especial como un "super cliente" privilegiado de la Unión Soviética. ${ }^{2}$ Ello, conjuntamente con las ventajas que obtuvo en el mundo a raíz a su internacionalismo, pesa mucho más que las ganancias económicas o diplomáticas que Cuba podría haber mantenido con los Estados Unidos si no hubiese enviado tropas a Africa.

Por su parte, ni los gobiernos de Ford ni de Carter podían aceptar ninguna de las incursiones, ya que cada una de ellas se percibía como un logro estratégico para la Unión Soviética y Cuba, y por lo tanto, como una derrota para los Estados Unidos en la lucha entre Oriente y Occidente. Adernás, ignorar las incursiones militares cubanas significaba correr el riesgo de fomentar aún más el afán aventurero de La Habana y ampliar en mayor medida el "imperio exterior" de la Unión Soviética so pretexto de la "distensión". De esta forma, el gobierno de Ford suprimió las conversaciones exploratorias secretas que había mantenido con representantes cubanos durante el período 1974-1975, luego del inicio de la operación en Angola en 1975.

El gobierno de Carter reaccionó de manera semejante a la operación conjunta cubano-soviética que repelió la invasión de Somalia a Etiopía en la disputada región de Ogaden. Para disminuir la dependencia de Cuba de los soviéticos, el gobierno de Carter había adoptado inicialmente una línea más conciliadora hacia La Habana, mediante los acuerdos de pesca y la creación de las "secciones de intereses" en abril de 1977. Ello hizo que el Ministro de Comercio Exterior y otros funcionarios cubanos visitaran los Estados Unidos para explorar la posibilidad de normalizar las relaciones comerciales y que, a su vez, algunos empresarios estadounidenses visitaran la Isla con el mismo propósito. Sin embargo, sólo tres meses después de que se abrieran las "secciones de intereses" en La Habana y Washington,

\footnotetext{
${ }^{2}$ Por ejemplo, pese à la gran caída del precio del azúcar en el mercado mundial, el acuerdo de comercio entre Cuba y la Unión Soviética de abril de 1976 estipuló que el precio más alto pagađo en 1975 por los soviéticos por el azúcar cubana constituiría el precio mínimo soviético bajo el nuevo acuerdo. Jorge I. Domínguez señal6 que "...el acuerđo para mantener el precio de 1975 fue, por lo tantò, un compromiso soviético sustancial para subsidiar el azúcar cubana. Más aún, el acuerdo se firmó justo cuando Cuba logró forzar a Suđáfrica para que retirara sus tropas de Angola." También indicó que "... comienzos de 1976, los subsiđios soviéticos al azúcar de Cuba (comparados con el precio real del mercado mundial) se hicieron masivos y superaron con creces el nivel de subsidio de la đécada de 1960". To Make a World Safe for Revolution: Cuba's Foreign Policy, (Cambridge: Harvard University Press, 1989), pp. 84-85.
} 
el gobierno de Carter descartó su actitud conciliadora, como consecuencia de la intervención cubano-soviética en Etiopía, ocurrida en noviembre de 1977. De ahí en adelante, cesaron las conversaciones para restablecer las relaciones comerciales con La Habana y el gobierno norteamericano adoptó una postura más dura frente a Cuba. $^{3}$

\section{Los intereses contradictorios en el "Nuevo Orden Mundial" de la década de los noventa.}

Con el término de la Guerra Fría y la desaparición de la Unión Soviética, los tipos de intereses contradictorios que giraron alrededor de la lucha entre Oriente y Occidente y que fomentaron el conflicto entre los Estados Unidos y Cuba ya no existen o, al menos, han perdido sus rasgos más característicos. Sin embargo, han surgido nuevos tipos de intereses contradictorios que ahora son un obstáculo para el acercamiento entre ambos países.

Pese a que resulta exagerado hablar de un "mundo unipolar", en que Estados Unidos ostenta la hegemonía indiscutible, los ideales estadounidenses y occidentales emergieron claramente como vencedores de la Guerra Fría. En la actualidad, existe un acuerdo prácticamente universal sobre la superioridad de los principios del sistema de mercado para organizar la economía de una nación y acerca de la necesidad del pluralismo y la democracia política. En este sentido, Francis Fukuyama tiene razón al hablar del "fin de la historia" , para aludir al término de las grandes batallas intelectuales de los siglos XIX y XX.

De esta forma, en el ex bloque oriental y en América Latina, respectivamente, se están reemplazando las economías socialistas o centralmente planificadas por sistemas más abiertos orientados al mercado. Pese a estar más presente en la retórica que en la práctica,

\footnotetext{
${ }^{3}$ Wayne S. Smith cree que los soviéticos y los cubanos estaban convencidos de que Estados Uniđos estaban đetrás de la invasión de Somalia a Etiopía, que se llevó a cabo después đe que el régimen de Siad Biarre había abandonado el lado estadounidense. "De esta forma, reaccionaron a lo que perciben cómo un movimiento agresivo nuestro. A su vex, Brzezinski consideró la reacción soviética como evidencia de que nos estaban probando. Su subsiguiente representación de acciones soviéticas y cubanas en el Cuerno, que demostraba un desacato a la distensión, turvo un efecto deletéreo en las perspectivas para el SALT y para un mejoramiento significativo de las relaciones con la Unión Soviética y con Cuba". The Closest of Enemies, (Nueva York: W. W. Norton \& Company, 1987), p. 136.
} 
también existe una conciencia creciente de que el pluralismo y la democracia liberal son necesarios para contrarrestar el peso potencialmente opresivo del Estado y para asegurar un óptimo crecimiento y desarrollo económico. A pesar de que no son necesariamente democráticos, han surgido sistemas más progresistas para reemplazar a los antiguos sistemas totalitarios o autoritarios existentes en gran parte de América Latina, en algunas partes de Europa del Este y en la ex Unión Soviética.

Pese a todas sus imperfecciones y problemas internos, Estados Unidos es el líder de este nuevo orden mundial sustentado en principios democráticos y del mercado y en el respeto por los derechos humanos. Justamente allí está el origen de los nuevos intereses contradictorios entre los Estados Unidos y Cuba.

\section{Los límites de la "liberalización" al estilo cubano.}

Pese a que durante su actual proceso de transición Cuba ha experimentado el proceso de liberalización económica más importante desde 1959, la Isla está muy lejos de tener una economía de mercado. Aún predominan las formas socialistas de propiedad y de dirección estatal de la economía. Hasta mediados de 1993, la liberalización estaba confinada al sector externo de la economía, en que Cuba estaba abierta a inversiones extranjeras en las áreas del turismo, la biotecnología y las exploraciones petroleras. Sin embargo, incluso este proceso de liberalización económica fue conducido, y aún lo es, por el Estado cubano, como lo aclaran los mismos reformadores cubanos. ${ }^{4}$ Mientras tanto, el mercado estuvo ausente de la economía interna, salvo por la creciente economía informal, que siguió siendo ilegal. Esta última fue tolerada por el gobierno sólo porque servía como una válvula de seguridad para los cada vez más desesperados consumidores cubanos de la Isla.

En el verano de 1993, el gobierno finalmente dio los primeros pasos para liberalizar la economía interna. En julio, anunció la

\footnotetext{
4 "El ímpetu de las políticas de reforma actuales proviene de las estructuras políticas cubanas. Existe consenso dentro del Partido Comunista Cubano... para una transición ordenada hacia un modelo diferente de organización social, destinado a reinsertar efectivamente a Cuba en el nuevo mundo de hoy... En Cuba, la opción parece clara: perseguir metas a largo plazo de reforma económica bajo control estatal". Pedro Monreal, "To market, to Market...", Hemisfile, vol. 4, №3, mayo-junio de 1993, p. 11. (Se ha añadido énfasis al comentario).
} 
E. González / Obstáculos que impiđen el acercamiento ...

llamada "dolarización" de la economía, que permite a los cubanos poseer legalmente moneda extranjera y que supuestamente aumentará las remesas de dólares provenientes de los exiliados cubanos en los Estados Unidos. La reforma también alivia un aspecto discriminatorio del denominado "turismo de apartheid", puesto que permite que los cubanos compren en tiendas que anteriormente se pagaba en dólares y que estaban destinadas exclusivamente a los extranjeros. ${ }^{5}$ En septiembre, se dio permiso a los cubanos para que se emplearan por cuenta propia en cerca de cien barcos, negocios y servicios que el gobierno no podía abastecer. Más tarde, durante ese mismo mes, se daría más autonomía a nuevos tipos de granjas cooperativas en un esfuerzo por aumentar las cosechas y la producción de alimentos.

Si bien el propósito de estas medidas consiste en aliviar la aguda contracción de la economía, éstas no necesariamente fomentan y respaldan la transición al sistema de mercado. Son esfuerzos del gobierno para regularizar las actividades ilegales del mercado, ya presentes en la economía informal, e incluso para explotar estas actividades en beneficio del Estado. Por ejemplo, en el caso de la dolarización, el gobierno procuró recaptar moneda fuerte en circulación mediante el alza inmediata de precios en las tiendas en que se paga en dólares. Mientras tanto, los otros dos decretos no son sólo concesiones dadas a contrapelo, sino también intentos por limitar las fuerzas del mercado.

De esta forma, el alcance del decreto sobre empleo por cuenta propia no sólo se limita a legalizar las actividades empresariales privadas que se encuentran en el mercado informal. También restringe la empresa privada a personas (o familias), siempre que no empleen a otras personas; probibe que los graduados universitarios, los médicos, los directores de empresas y el personal gerencial participen en dichas actividades, y además hace un llamado a las autoridades locales para que se aseguren de que los "intermediarios y parásitos" no se aprovechen del decreto. ${ }^{6}$ En efecto, el decreto es más restrictivo que los que regían la realidad económica cubana en la década de los sesenta, antes de la "ofensiva revolucionaria" de 1968, y difícilmente constituye un paso de "vuelta al futuro". En lugar de constituir

\footnotetext{
${ }^{5}$ Sin embargo, los cubanos aún deben ser acompañados por extranjeros para entrar a los restaurantes, clubs nocturnos y hoteles que están reservados para los turistas extranjeros.

${ }^{6}$ Pascal Fletcher, "Communist-Ruled Cuba Moves Closer to Mixed Economy", Reuter, 9 de septiembre de 1993.
} 
una acción significativa hacia la liberalización de la economía interna, trae a la memoria los gremios de los tiempos medievales.

El decreto de cooperación agrícola escasamente promueve las cooperativas cubanas mucho más allá de la condición de las viejas granjas colectivas soviéticas pertenecientes al Estado. Según se estipula en el decreto, los agricultores cubanos gozan del uso indefinido de la tierra, pero no de la propiedad legal de la misma y, peor aún, deberán vender sus cosechas a organismos estatales de compra a precio fijo y no al precio del mercado. ${ }^{7}$ En consecuencia, es posible que los principales productores agrícolas continúen eludiendo el régimen, a menos o hasta que el gobierno promulgue reformas más radicales orientadas al mercado, incluido el restablecimiento del mercado libre de los campesinos que Castro abolió en 1986.

Mientras tanto, la apertura de la organización política cubana ha sido incluso menor que la apertura económica de la Isla. El mando de un hombre, un partido, permanece indisputable. Se concede muy poco espacio político fuera del régimen y sólo deniro de parámetros estrictamente impuestos que prohiben la desviación política.

Por ejemplo, en tanto que la Constitución enmendada en 1992 permite a los ciudadanos cubanos algunas libertades y derechos civiles personales, éstos siguen concediéndose de manera condicionada al igual que bajo la Constitución original de 1976. En el artículo 62 , se estipula que "ninguna de las libertades... puede ejercerse de manera contraria a lo estipulado en la Constitución y en las leyes o contraria a la decisión del pueblo cubano para construir el socialismo y el comunismo. La infracción de este principio es penada". ${ }^{8}$ En efecto, el sistema estatal de control -que comprende el Ministerio del Interior (MININT), los Comités para la Defensa de la Revolución dirigidos por el partido y las recién creadas brigadas de reacción rápida dirigidas por personal del MININT- tiene autoridad legal para tomar medidas enérgicas en contra de aquellos ciudadanos cubanos que sean lo suficientemente valientes como para criticar u oponerse abiertamente al gobierno.

En el nombre de la mantención de la unidad revolucionaria, la unanimidad y el socialismo, la oposición política organizada se tolera en Cuba incluso menos que en los sistemas autoritarios de México,

\footnotetext{
${ }^{7}$ Véase "Acuerdo đel Buró Político para llevar a cabo importantes innovaciones en la agricultura estatal", Granma, 15 de septiembre de 1993, p. 1.

${ }^{8}$ FBIS-LAT-92-226-S, 23 de noviembre de 1992, p. 7.
} 
previos al gobierno de Salinas de Gortari, o de Chile durante el régimen de Pinochet. La sociedad civil cubana sigue siendo mucho más débil y reprimida por el Estado que la de sus contrapartes en los sistemas autoritarios de México y Chile. Si bien Cuba no ha sido testigo de la brutal represión y de los masivos crímenes políticos como los de El Salvador y Guatemala, el régimen de Castro bien podría hacer uso de formas semejantes de represión opresiva si no se supera la crisis actual y las masas comienzan a rebelarse. Mientras tanto, se siguen violando los derechos humanos individuales, especialmente aquellos de los disidentes y críticos políticos del poder vigente, en parte, porque el régimen considera que el control estricto y la represión pueden impedir una confrontación como la ocurrida en Tiananmen. ${ }^{9}$ Como mínimo, Cuba sigue siendo un Estado autoritario "postotalitario" que muestra pocos signos de que allí pudiera instaurarse un mandato más pluralista y progresista, a diferencia de sus vecinos de América Latina y el Caribe y gran parte del mundo.

\section{Repercusión de las políticas para los Estados Unidos.}

La situación actual de Cuba hace difícil para los Estados Unidos buscar algún tipo de acuerdo con el gobierno de Castro, puesto que hacerlo implicaría abandonar su compromiso con el sistema de mercado, la democracia y los derechos humanos. Por supuesto, esos principios no impidieron que los gobiernos de Bush y de Clinton renovaran la condición de nación más favorecida a China, a pesar del poder represivo del gobierno de ese país y de la considerable oposición del Congreso. En realidad, los casos de Cuba y China parecieran ser semejantes. Al igual que Cuba, China está experimentando una transición del comunismo bajo la fórmula de "leninismo de mercado", según la cual el Partido Comunista chino ha liberalizado considerablemente la economía, mientras mantiene un estricto control político sobre la sociedad. Sin embargo, China difiere de Cuba en varios aspectos importantes.

\footnotetext{
${ }^{9}$ En 1992, un alto funcionario cubano señaló a Gillian Gunn que el gobiernoprefería "arrestar ahora a los disidentes en lugar de fusilarlos más tarden. Esto fue mencionađo por Gillian Gunn al hablar sobre "la situación actual de Cuba" en la conferencia de la Americas Society, "Cuba at the Turning Point", Nueva York, 13 de marzo de 1992.
} 
Cuba no es China con sus más de mil millones de habitantes, su enorme y creciente mercado interno, sus inversiones estadounidenses y sus vínculos económicos con Occidente. Tras sobrevivir a la muerte de Mao en 1976 y haber estado a la cabeza de la economía de más rápido crecimiento del mundo, el régimen comunișta chino permanece firme en el poder, sin demostrar ningún signo de un posible colapso u otra opción de gobierno. Por el contrario, el régimen de Castro bien pudiera ser un régimen que agoniza como consecuencia de la crisis cada vez más intensa que prevalece en la Isla. Finalmente, la comunidad china en los Estados Unidos, que al parecer es menos influyente que la cubana, no se opone a las relaciones diplomáticas y económicas con Beijing.

No obstante, quienes abogan por una moderación de la política estadounidense hacia el gobierno de Castro lo hacen por varias razones. Se podrían atender los intereses diplomáticos al levantar el embargo estadounidense -especialmente la Cuban Democracy Actya que se eliminaría un motivo de irritación importante en las relaciones de Estados Unidos con Canadá, Europa Occidental y América Latina. También se obtendrían ventajas económicas, ya que las empresas turísticas, comerciales y manufactureras de Estados Unidos podrían ser capaces de invertir en Cuba, o negociar con ese país, antes de que la Isla sea bloqueada por competidores europeos, canadienses y latinoamericanos. Sin embargo, estas consideraciones diplomáticas y económicas no constituyen en sí mismas argumentos imperiosos para normalizar las relaciones con un régimen que puede hallarse en un estado de crisis terminal y que, en todo caso, no está comprometido con el sistema de mercado, la democracia ni los derechos humanos.

Por otra parte, los críticos estadounidenses más progresistas y de izquierda sostienen que un cierto tipo de "compromiso positivo" con La Habana fomentaría los intereses políticos de los Estados Unidos. El hecho de levantar el embargo y mitigar la crisis económica de la Isla, que a juicio de ellos ablandaría la mentalidad de aislamiento del régimen de Castro, contribuiría a la apertura de Cuba, fortalecería los elementos de reforma del régimen y, en consecuencia, facilitaría la transición hacia una sociedad más pluralista y orientada al sistema de mercado. Lo más importante es que ese paso bien podría impedir una posible explosión política que ocasionaría nuevas olas de emigración y que conduciría a una probable intervención armada de los Estados Unidos a Cuba. 
La condición para el "compromiso positivo" se basa en ciertos supuestos cuestionables. La difícil situación económica de Cuba no ha sido causada por el embargo estadounidense, sino por la desaparición de sus anteriores protectores del bloque comunista y por las propias políticas fallidas del régimen y la resistencia continua al cambio esencial de sistema, que algunos críticos estadounidenses convenientemente pasan por alto. ${ }^{10}$ Más importante aún, no hay certeza de que el levantamiento del embargo, ya sea condicional o incondicional, fortalezca a los reformadores y facilite la transición hacia una economía de mercado y una organización política más abierta, como suponen muchos de los que proponen un cambio político. ${ }^{11}$ De hecho, puede ocurrir la situación inversa.

El levantamiento del embargo bien podría congelar o tal vez incluso retardar el proceso de reforma, lo que dejaría un régimen autoritario que, en el mejor de los casos, se sustentaría en un sistema económico más liberalizado. Castro y los sectores intransigentes, y no los reformadores de mentalidad más progresista, son los que manejan los elementos de poder en el partido, el ejército y los organismos estatales de seguridad. Este mandato conservador y autoritario resiste, destruye y limita las reformas progresistas. La afluencia de dólares introducidos por los turistas estadounidenses acabaría con los incentivos de Castro, de los sectores intransigentes y de los centristas de aceptar la necesidad de una liberalización económica más profunda y especialmente política. De ser así, la política estadounidense habría asegurado la supervivencia del régimen bajo un cierto tipo de "leninismo de mercado".

Una experiencia negativa de este tipo expondría al gobierno de Clinton a serios ataques, no sólo de los conservadores cubano-estadounidenses, sino también de los círculos republicanos, demócratas y de los defensores de los derechos humanos. Su apatía hacia el régimen de Castro no reside simplemente en su bagaje emocional de la Guerra Fría, como sostienen algunos críticos. Esencialmente, proviene de un profundo desagrado por el tipo de orden político-económico que el gobierno de Castro ha mantenido durante los últimos

\footnotetext{
${ }^{10}$ Por ejemplo, véase Jesse Jackson, "We May Get Burned by the Cuba Embargo", Los Angeles Times, 28 de noviembre đe 1993, p. MS.

${ }^{11}$ En relación con ejemplos más recientes, véase el trabajo de Andrew Zimbalist, "Dateline Cuba: Hanging on in Havana", Foreign Policy, 1993, p. 151-167, que aparece traducido en esta revista, y un estudio más extenso de Gillian Gunn, titulado Cuba in Transition: Options for $U$. S. Policy, (Nueva York: A Twentieth Century Fund Paper, 1993).
} 
treinta y cuatro años, que probablemente no cambiará con los actuales gobernantes y que podría prolongarse mediante concesiones estadounidenses importantes. ${ }^{12}$

¿Por qué, entonces, el gobierno de Clinton debe tomar la iniciativa frente a Castro cuando el asunto cubano ciertamente constituiría una desventaja política en un momento en que el gobierno está preocupado de otras prioridades y crisis de política exterior? ¿Por qué arriesgar la recién establecida estatura y autoridad del Presidente Clinton en el Congreso, tras su victoria con el Tratado de Libre Comercio de América del Norte y su éxito en las reuniones sostenidas con los líderes de Asia, al hacer algo con Cuba que bien podría prolongar el mandato de Castro en lugar de apresurar su partida?

\section{La resistencia cubana al cambio esencial de sistema.}

Entre tanto, Cuba aparece atrapada por el término de la Guerra Fría y por su propio gobierno, sus políticas internas y su historia. Fidel Castro corrió un gran riesgo al realinear a Cuba con la Unión Soviética en 1960. Por casi tres décadas, se compensó ese riesgo, pero ahora ha terminado en una catástrofe, ya que Cuba ha quedado desprovista de un sistema de apoyo internacional tras la caída del comunismo y la Unión Soviética. Como consecuencia, su régimen no tiene otra alternativa que integrar a Cuba en el sistema internacional, es decir, en un sistema occidental democrático y orientado al mercado.

Ello presenta un gran problema para Castro y otros líderes cubanos de su generación que tiene que ver con la identidad misma de la Revolución Cubana y que limita el alcance de la liberalización en la Isla. Para la mayoría de los líderes cubanos, el "mercado" se identifica con los "demonios del capitalismo" y, el capitalismo, con los Estados Unidos y Cuba antes de 1959. De esta forma, el "socialismo" se transformó en el antídoto después de 1959. Éste era la antítesis

\footnotetext{
${ }^{12}$ En una audiencia conjunta sobre Cuba acordada por tres comités de la Cámara de Representantes el 18 de noviembre, el representante Tom Lantos condenó ácidamente el régimen de Castro, tras una visita de una semana a Cuba. El demócrata liberal nacido en Hungría, comparó a Cuba con la Europa del Este de Stalin y advirtió que la continua rigidez đel régimen haría prácticamente imposible llegar a acuerdos con ésta. CubaINFO, vol.5, №15, 24 de noviembre de 1993, p. 2.
} 
del capitalismo y ofrecía la liberación nacional y los medios para obtener un defensor internacionalmente poderoso para Cuba. Al igual que en otros sistemas marxista-leninistas y autoritarios, este compromiso con el socialismo refleja una preferencia muy arraigada por utilizar instituciones, como el Estado, el partido, el ejército yotras destinadas a organizar y administrar la economía, como asimismo, una profunda aversión a depender del mercado. ${ }^{13}$

De esta forma, sibien una generación más joven de economistas cubanos puede referirse a la adopción de los principios del sistema de mercado en Cuba, o incluso abogar por los mismos, hablar del mercado está notablemente fuera del discurso político de Castro, Ramón Machado Ventura y otros líderes del partido. Adoptar el sistema de mercado no sólo acabaría virtualmente con la identidad de la revolución, sino también significaría que los líderes cubanos han cometido un enorme error histórico. No se puede aceptar ningún error como ése, señaló Castro el pasado 26 de julio, cuando, al referirse a la otrora Unión Soviética, declaró que "se debería haber perfeccionado el socialismo en lugar de destruirlo". ${ }^{14}$

$\mathrm{El}$ mismo hecho de que se evite el mercado como simbolismo político indica que el actual proceso de transición cubano dejará de introducir verdaderas reformas de mercado, incluida la privatización de segmentos importantes de la economía interna. Como se mencionó anteriormente, así ha ocurrido hasta ahora. Sin embargo, también es probable que el carácter limitado del proceso de reformas continúe por razones más prácticas que trascienden el simbolismo político y la ideología.

El sistema de mercado, al igual que la democracia, conduce a la pérdida del control estatal sobre la sociedad, lo que Castro, los sectores intransigentes e incluso los centristas más moderados y pragmáticos no quieren permitir. El mercado arrancaría la facultad de adoptar decisiones económicas de la tuición directa del régimen

\footnotetext{
${ }^{13}$ David Ronfeldt sostiene la teoría de que las sociedades occidentales han evolucionado primero en términos de instituciones jerárquicas, seguidas más tarde por mercados competitivos, con redes multiorganizacionales que emergen actualmente como la próxima forma de organización đe la sociedad. Por razones de ideología, poder y seguridad estatal, los regímenes comunistas se mantuvieron en la etapa institucional de desarrollo, lo que les hizo difícil adoptax más tarde el mercađo. Véase David Ronfeld̄t, Institutions, Markets, and Networks: Toward a New Framework, RAND, en preparacion. En David Ronfeldt y Cathryn L. Thoroup, North America in the Era of Citizen Networks (DRU-459-FF), Santa Mónica, RAND, agosto de 1993, se presenta un resumen preliminar y una aplicación del marco teórico.

${ }^{14}$ FBIS-LAT-93-142, 27 de julio de 1993, p. 8.
} 
para dejarla en manos de productores, comerciantes y consumidores, y promovería una clase empresarial y una sociedad civil cada vez más independiente del Estado. Además, frustraría los esfuerzos del régimen por inculcar los valores socialistas en la sociedad.

Asimismo, el sistema de mercado, al hacer surgir nuevos ganadores y perdedores, ciertamente erosionará la base tradiciónal de sustentación política del régimen. Como se demostró con la introducción de los mercados libres de los campesinos en 1980, la existencia de un mercado informal y la reciente dolarización de la economía, los principales apoyadores del régimen son precisamente los que se ven menos beneficiados por las reformas del mercado. Por ejemplo, ya que sólo 3\% de la comunidad cubana exiliada en los Estados Unidos es afrocubana, los negros y mulatos de la Isla casi no se beneficiarían directamente con las mayores remesas que ingresaran ahora a Cuba. También sería probable que los miembros del partido, los funcionarios de gobierno, los oficiales y reclutas militares y otras personas que viven con ingresos fijos experimentaran una sensación creciente de privación relativa. Ello, por cuanto podrían compararse con los cubanos que trabajan como intermediarios y comerciantes en el mercado negro, que prestan servicios en el negocio del turismo como choferes de taxi, "jineteras" y "jineteros" (prostitutas y "alcahuetes") o que laboran en el sector externo de la economía y prosperan en materia financiera, en tanto que ellos, que políticamente lo merecen, deben soportar crisis agudas y un nivel de vida cada vez más bajo.

Las reformas democráticas presentan una amenaza incluso mayor para la mantención de la hegemonía y el control político del régimen sobre la sociedad. Como se observó con la caída del comunismo en Europa del Este y en la Unión Soviética, la descompresión política -especialmente en su modalidad de democratización- está llena de riesgos, más aún cuando Cuba experimenta una aguda crisis económica y aumenta el descontento popular. Si bien se libera a los presos políticos, no se puede compartir el poder político, ni menos renunciar a él. El poder debe permanecer concentrado en las manos de Castro, la "nomenklatura" y el Partido Comunista de Cuba (PCC).

En consecuencia, tanto en la teoría como en la práctica, las "reformas" políticas cubanas recientemente aprobadas casi no se asemejan a los principios democráticos, ya que el régimen continúa manejando el campo de juego para asegurar su monopolio del poder político: 
No obstante, pese a que el partido ya no representa exclusivamente al proletariado, sirve como "la vanguardia organizada de la nación cubana", según la Constitución enmendada en 1992.

En una enmienda constitucional de 1992, se pide la elección directa de los delegados de las Asambleas Municipales y de la Asamblea Nacional del Poder Popular (ANPP). Sin embargo, según la ley electoral de 1992, los candidatos son examinados por comisiones electorales a nivel municipal y nacional, mientras que la Comisión Nacional de Candidatura nomina a la mitad de los candidatos de la ANPP para "evitar improvisaciones innecesarias en el proceso de nominación" ${ }^{15}$ Según lo señaló un observador posteriormente, "... el Partido Comunista no podía tolerar ni siquiera la posibilidad de que un pequeño número de delegados de la oposición participara en las asambleas". 16

En las elecciones de la ANPP celebradas en febrero de 1993, se presentó al electorado una lista única con 589 candidatos, es decir, el mismo número de asientos existentes en la ANPP. Además, el régimen hizo un gran esfuerzo para convencer a los votantes de que debían aprobar la lista completa del gobierno, ya que un voto parcial o negativo, o las papeletas manchadas o en mal estado, sería equivalente a la traición. ${ }^{17}$

La campaña del régimen dio resultado. A pesar de que no se obtuvo unanimidad, se informó que $88.48 \%$ de los electores dio su voto a la lista completa de candidatos de la ANPP, de la cual se había excluido a la oposición. ${ }^{18}$

En resumen, Cuba está en transición, pero no se sabe hacia dónde. Las reformas del régimen no alcanzan a llevar a la economía y a la organización política hacia el sistema de mercado y la democratización. Si se formula una hipótesis a partir de las políticas y tendencias actuales, lo mejor que se puede esperar del régimen de Castro es que combine la liberalización económica con el autoritarismo político. De ser así, la economía política cubana podría llegar a parecerse a los modelos de China postmaoísta o de México antes de -1982, o mejor aún, a un sistema híbrido que incorpora elementos del

\footnotetext{
${ }^{15}$ Trabajadores, 26 de octubre de 1992; y FBIS-LAT-208-A, 27 de octubre de 1992, p. 1.

${ }^{16}$ Marifeli Perez-Stable, "Vanguard Party Politics in Cuba", en: Enrique A. Baloyra y James A. Morris (comps.), Conflict and Change in Cuba, (Albuquerque: University of New Mexico Press, 1993), p. 83.

${ }^{17}$ CubalNFO, vol. 5, N\$3, 26 de febrero de 1993, p. 5.

${ }^{18}$ CubaINFO, vol. 5, Ne4, 19 de marzo de 1993, p. 7.
} 
modelo cubano actual con elementos de los modelos chino y/o mexicano. De aplicarse cualquiera de estos modelos, el panorama para el sistema de mercado y la democratización sigue siendo prácticamente negativo, al igual que la perspectiva de recuperación económica de la Isla. ${ }^{19}$ En estas circunstancias, resulta difícil concebir que el gobierno de Clinton lance un salvavidas al gobierno cubano.

\section{La crisis como otro impedimento para el ajuste.}

El mismo hecho de que Cuba permanezca en una "crisis persistente", para utilizar la frase de Jorge Domínguez, disminuye aún más los incentivos del Gobierno de los Estados Unidos de buscar una solución al problema cubano. Por una parte, la crisis aún no ha llegado a un punto tan crítico como para obligar a los más altos encargados de formular las políticas gubernamentales a prestar atención a Cuba, especialmente cuando existen asuntos internacionales más importantes en el mundo que consumen tiempo y energía. Por otra parte, algunos funcionarios norteamericanos encargados de formular las políticas de ese país pueden suponer que la crisis llevará finalmente a la caída del gobierno de Castro y, con ello, al logro de los intereses estadounidenses en el largo plazo. De ser así, ¿por qué debe Washington tomar la iniciativa de hacer algo que podría permitir a Castro y su régimen sobrevivir en un momento en que parecen estar en una situación precaria?

La crisis también afecta al gobierno de Castro en dos sentidos. Por el momento, ha permitido que los reformadores persuadan a Castro y a los sectores intransigentes de que comiencen a abrir la economía, porque en cierto modo no existe ninguna otra forma de superar la crisis. A su vez, el carácter incipiente de la sociedad civil, la apatía de las masas, la carencia de alternativas viables al régimen y el propio poder institucional y político del Estado, hasta ahora han permitido al gobierno promulgar reformas limitadas sin que se logre solucionar la situación política. Sin embargo, el mismo hecho de que el régimen aún tenga el control de las calles también debilita la

\footnotetext{
${ }^{19}$ En relación con un conjunto de evaluaciones más coherente que presenta conclusiones semejantes relativas a la decadencia política y económica actual de Cuba y sobre el futuro oscuro de la Isla, véase Instituto de Investigaciones Cubano, Transition in Cuba: New Challenges for U. S. Policy, (Florida International University, 1993).
} 
posibilidad de promulgar otras reformas. Mientras tanto, la debilidad de la sociedad civil y especialmente la ausencia de un sector privado organizado, dejan a los reformadores sin los aliados y el apoyo externos que podrían ejercer presión para acelerar y profundizar el proceso de liberalización.

Existe otra forma en que la crisis puede afectar el comportamiento del régimen. Frente al telón de fondo de heroísmo y martirio de la historia cubana, la cultura política dominante de Castro y de gran parte del gobierno cubano ha consistido en valorar la lucha, la intransigencia y el desafío. Someterse o rendirse no son parte del vocabulario del régimen; muerte y martirio les resultan palabras más adecuadas, como lo descubrieron los oficiales militares cubanos en Granada. ${ }^{20}$ Esta cultura del heroísmo y el martirio sugiere que los reformadores en Cuba no pueden presionar demasiado para obtener cambios o concesiones fundamentales, por miedo a ser acusados de aceptar el capitalismo y el imperialismo.

En menor grado, la cultura de élite indica que Castro y los líderes intransigentes podrían preferir terminar en una confrontación, si la crisis se volviera incontrolable y el régimen se encontrara en un "callejón sin salida". Frente a esa encrucijada, el régimen se inclinaría por detener el proceso de reforma y restablecer la flexibilidad con una intransigencia y desafío renovados, tanto en el país como en el extranjero. Como mínimo, el régimen recurriría a una mayor represión para restaurar el orden y permanecer en el poder, como lo demostró, en agosto pasado, Jorge Lescano Pérez, Secretario del pcc de La Habana, cuando instó a los grupos vigilantes de los ciudadanos para que actúen con firmeza contra el aumento de los delitos e incidentes callejeros, en que se arrojan piedras durante los apagones nocturnos de la ciudad. ${ }^{21}$ No obstante, si los controles más estrictos no impiden que la situación interna se solucione, Castro y sus seguidores podrían buscar una última confrontación decisiva con los Estados Unidos, con la esperanza de recobrar la confianza de los

\footnotetext{
${ }^{20}$ Nelson $P$. Valdés señala que "la muerte permeabiliza la imaginación política e histórica de Cuba" y que muchas figuras políticas han muerto "para demostrar que han tenido los mejores intereses del país en mente y que han sostenido los estandartes patrióticos y morales en alto". "Cuban Political Culture: Between Betrayal and Death", en: Sandor Halebsky y John M. Kirk (comps.), Cuba in Transition: Crisis and Transformation, (Boulder. Westview, 1992), p. 221. El mismo tema también es examinado por Edward González y David Ronfeldt, Cuba Adrift in a Postcommumist World, R-4231-USDP, Santa Mónica, RAND, 1992, en su debate sobre la tradición cubana de "resistencia y lucha", resumiđa por José Martí y por el propio Castro, p. 41.

${ }^{21}$ Los Angeles Times, 30 de agosto de 1993, p. A4.
} 
cubanos nacionalistas en torno al régimen y salvaguardar su lugar en la historia, aunque ello llevara a un final como el de Gotterdammerung. 22

Sin embargo, de manera perversa, la crisis parece actuar como un freno para ambas partes. En Washington, algunos pueden preferir la inactividad, en parte, debido a sus supuestos en relación con el posible resultado de la crisis de la Isla. Por su parte, los círculos más intransigentes del régimen de Castro pueden considerar la crisis como un momento definitivo para la Revolución Cubana en que no puede existir ningún tipo de compromiso con los Estados Unidos.

\section{Algunas conclusiones sobre las opciones de política estadounidenses.}

Según el análisis anterior, el origen del estancamiento de relaciones entre los Estados Unidos y Cuba es histórico; está fundado en las respectivas funciones y autoimágenes internacionales de ambas partes y en consideraciones políticas nacionales de las élites dirigentes estadounidenses y cubanas. Desde la perspectiva de la política norteamericana, no existen soluciones fáciles para encarar la situación de estancamiento, tema tratado en nuestro estudio RAND de 1992, en que se analizan las ventajas y desventajas de las diferentes opciones que podría adoptar la política estadounidense. ${ }^{23}$

Desde que se concluyó ese estudio, Cuba ha experimentado algunos cambios significativos. La economía ha continuado empeorando en forma sostenida, al igual que el sufrimiento de la población cubana. Algunos líderes progresistas más jóvenes han alcanzado puestos muy altos y se han promulgado algunas reformas económicas

\footnotetext{
${ }^{22}$ En relación con una mayor elaboración, véase Edward González y David Ronfeldt, op. cit, pp. 54-59. La extensa red de refugios y túneles que se ha construido bajo La Habanay en otras ciuđades, y que continúa construyéndose a pesar de la crisis económica de la Isla, hace que una confrontación al estilo Gotterdammerung o de Numancia (en que los defensores de la guarnición española prefirieron el suicidio en lugar đe la rendición), sea posible en un régimen de Castro en estado agonizante.

${ }^{23}$ Terminado antes de la aprobación de la Cuban Democracy Act, nuestro estudio RAND rechazó las alternativas políticas de aumentar y disminuir las presiones. En cambio, recomendamos la opción de mantenerse constante, pero con una política đe información y comunicación. Bdward González y David Ronfeldt, op. cit, pp. 60-82. Véase también Donald E. Schulz, The United States and Cuba: From a Strategy of Conflict to Constructive Engagement, (Carlisle Barrack, Pa.: Strategic Studies Institute, U. S. Army War College, 1993).
} 
limitadas. Sin embargo, Castro y sus primeros secretarios provinciales aún controlan el sistema del partido. Ellos, en conjunto con otros elementos intransigentes del ejército y de las fuerzas de seguridad, siguen siendo las fuerzas dominantes del régimen. Pese a que aún carecen de identidad, existen algunos signos de inquietud creciente en el pueblo, que podrían conducir a una mayor represión del gobierno, o bien, si empeora la situación económica y fallan los controles, a la inestabilidad y a una posible guerra civil en la Isla.

Ala luz de estos acontecimientos y perspectivas, ¿debería acaso modificarse la política estadounidense para tratar de aliviar la situación apremiante del pueblo cubano, influir en el resultado del actual proceso de transición en ese país e impedir así una posible matanza en la Isla? Como ya se señaló, algunos críticos sostienen que el embargo económico estadounidense debería levantarse no sólo por razones humanitarias, sino también por motivos políticos, pues se fortalecería a los reformadores, al eliminarse la amenaza externa estadounidense y se les daría más espacio político. Se cree que ello aumentaría las perspectivas de una mayor liberalización en el corto plazo y de una transición pacífica que, en el largo plazo, conduciría a Cuba hacia una futuro orientado a la democracia y al sistema de mercado. De ser así, la política estadounidense podría entonces lograr un "aterrizaje suave" en Cuba.

Como se señaló anteriormente, el problema de este modo de pensar consiste en que la crisis económica actual de Cuba reside en las políticas gubernamentales pasadas y en la oposición continua de Castro a las reformas del mercado del mundo desarrollado. Aunque se levantara el embargo, el Gobierno de Cuba aún necesitaría conseguir créditos de los Estados Unidos para poder importar productos de ese país, lo que es poco probable a estas alturas. La solución para afrontar la difícil situación económica de Cuba no depende tanto del levantamiento del embargo, como de que el propio gobierno cubano se mueva rápidamente hacia el mercado y la privatización de la economía de la Isla. Como ha concluido un especialista en asuntos económicos cubanos, lo que el gobierno debe hacer es "...insertar la economía mundial en la economía planificada de Cuba". ${ }^{24}$

Mientras tanto, la crisis cubana ha llevado así a la mayor liberalización económica desde 1959 y existen rumores de que habrá más

\footnotetext{
${ }^{24}$ Sergio G. Roca, "The Comandante in his Economic Labrynth", en: Baloyra y Morris (comps.), op. cit, p. 105.
} 
reformas a fines de 1993 o comienzos de 1994. De este modo, se puede contraargumentar de que la política estadounidense debe permanecer constante para mantener la eficacia del "doble embargo" -el primero, causado por la política estadounidense y, el segundo, por la caída de la Unión Soviética- como un medio para asegurar reformas aún mayores. Por el contrario, como ya se indicó, disminuir el embargo podría permitir que Castro y los elementos más intransigentes del gobierno hicieran más lento o detuvieran todo el proceso de reforma, lo que dejaría un régimen autoritario arraigado en la Isla.

Por otra parte, no se verían beneficiados los intereses de los Estados Unidos ni los del pueblo cubano si la crisis de la Isla acabara en un disturbio político o, peor aún, en una guerra civil. Un oscuro futuro como éste para Cuba ciertamente daría lugar a una prolongada inestabilidad política, un mayor conflicto racial, la emigración masiva y el aumento del narcotráfico y otras actividades delictivas, derivadas del debilitamiento y de la deprivación del Estado y la sociedad. Cuba, devastada y dominada por los conflictos, repercutiría directamente en los Estados Unidos.

Claramente, existen riesgos para la acción y la inacción estadounidenses, y el hecho de tener Estados Unidos una especie de fijación con respecto a Cuba bajo el mando de Castro, contribuyen a que pierdan de vista sus intereses más duraderos en Cuba después del gobierno de líder cubano. En el estudio RAND de 1992, se mostró una posición contraria a la "intervención humanitaria", salvo en caso de circunstancias extremas, debido no sólo a los grandes costos militares y diplomáticos que ello implica, sino también al hecho de que aquélla dejaría un legado en ruinas tanto para un gobierno posterior a Castro como para las futuras relaciones entre los Estados Unidos y Cuba y entre los países del hemisferio. En consecuencia, Estados Unidos necesita alcanzar simultáneamente objetivos de corto y largo plazo en relación con Cuba con y sin Castro. Al tratar con Castro, Estados Unidos debe evitar fortalecer su poder, mientras se prepara para los peores resultados posibles de la actual crisis, incluidos una creciente intranquilidad política y una posible guerra civil. Al mismo tiempo, Estados Unidos también debe preparar las bases para una futura relación con Cuba y el pueblo cubano, aunque exista cierto riesgo de que la posición de Castro en el corto plazo pudiera repuntar marginalmente.

¿Cómo pueden estos intereses estadounidenses aparentemente contradictorios -que abarcan las consideraciones de corto y largo 
plazo y a Cuba cony sin Castro-comenzar a reconciliarse? En primer lugar, los encargados norteamericanos de formular las políticas de ese país deben partir de la base de que es probable que no ocurra una liberalización significativa de la economía y la organización política cubana mientras Castro y los "fidelistas" a ultranza permanezcan en el poder. No obstante, Washington podría emprender ciertas iniciativas unilaterales a corto plazo que evitarían dar una ventaja política o económica indebida a Castro e incluso disminuir la hostilidad estadounidense y ayudar directamente al pueblo cubano. Las iniciativas de más largo plazo deberían estar centradas en fomentar el posible surgimiento de una economía de mercado, una sociedad civil y un gobierno cubano democrático posterior a Castro.

La nueva política del Pentágono de informar a las autoridades cubanas sobre los inminentes ejercicios militares en Guantánamo y el programa propuesto por el gobierno para mejorar las telecomunicaciones con la Isla, son pasos que anticipan los objetivos políticos estadounidenses de corto y largo plazo. El primero de ellos disminuye la percepción cubana de que existen amenazas y, el segundo, procura utilizar mayores flujos de comunicación para promover los elementos de una sociedad civil en Cuba. Otro paso consistiría en aflojar las restricciones del embargo para permitir la venta y suministro de alimentos, como asimismo el funcionamiento de los servicios de salud y otros tipos de asistencia humanitaria a Cuba, todo lo cual contribuiría a aliviar el conflicto actual de la población de la Isla. También se podrían fomentar los vínculos entre las organizaciones no gubernamentales estadounidenses y cubanas. Si con el tiempo estos pasos iniciales llevaran a una mejor observancia de los derechos humanos por parte del gobierno cubano y a claros signos de que éste avanza hacia una economía de mercado y hacia una liberalización política, éstos podrían aumentarse posteriormente mediante concesiones estadounidenses más explícitas, incluido el levantamiento selectivo de algunos aspectos del embargo. ${ }^{25}$

No obstante, ya que Castro no es ningún ejemplo en materia de liberalización económica ni política, es probable que su gobierno

\footnotetext{
${ }^{25}$ Al utilizar un modelo teórico, John Arquilla sugiere la manera en que los Estados Unidos podrían tratar de "probar" el clima cubano al tomar iniciativas cautelosas y esperar su repercusión antes de tratar de conseguir mayores concesiones. Véase $A$ Decision Modeling Perspective on U. S.-Cuban Relations (MR-377-USDP), Santa Mónica, RAND, 1993. En relación con un ejemplo de estrategia de alternativa en que las concesiones estadounidenses se hacen menos contingentes en el comportamiento cubano, véase Gunn, op. cit, pp. 75-93.
} 
detenga el proceso de reformas y aumente la represión del Estado. Dichas políticas regresivas podrían ponerse en práctica si Castro considera que las reformas van muy lejos, que su régimen pierde el control y/o que aumenta la intranquilidad popular. Si ocurriera ese tipo de regresión, Estados Unidos tendría que suspender o cancelar sus anteriores concesiones, no sólo debido a sus políticas internas, sino también a que la política estadounidense procura una apertura para Cuba y no una recompensa para un gobierno opresivo.

Un enfoque mesurado como el descrito corre el riesgo de ser sobrepasado por otros acontecimientos en la Isla; sin embargo, concuerda con los ideales estadounidenses de índole humanitaria, los derechos humanos, ellibre mercado y la democracia. También se basa en una evaluación más realista de la realidad cubana actual, en el sentido de que no se sustenta en la dudosa premisa de que un cambio en la política estadounidense puede hacer que Castro adopte un nuevo rumbo o, independientemente de quién sea el "líder máximo", lograr un sistema de cambio fundamental en Cuba. La invasión estadounidense como incitación para que Castro deje el poder parece ser altamente improbable en este momento. El destino cubano probablemente será decidido por el mismo pueblo cubano, a su propio ritmo, más que por cualquier acción que Estados Unidos lleve a cabo como parte de su política hacia La Habana. 